\title{
TENSILE AND FLEXURAL TEST ON GLASS FIBRE REINFORCED EPOXY COMPOSITE
}

\author{
Shaik Javeed ${ }^{1}$, S. Venkateswarulu ${ }^{2}$
}

\begin{abstract}
Since the early 1960s, there has been an increase in the demand for stronger, stiffer and lighter weight materials for use in the aerospace, transportation and construction industries. High performance demands on engineering materials have led to extensive research and development of new and improved materials such as composites. Composite materials used for structural purpose often have low densities, resulting in high stiffness to weight and high strength weight ratios when compared to traditional engineering materials. In addition, to the high fatigue strength to weight ratio and fatigue damage tolerance of many composites also makes them an attractive option. As a result, composite materials are rapidly being utilized in industries that have traditionally used metals, and are now at the forefront of research and development in many related areas.

The overall objective of the present work is to prepare glass fibre reinforced epoxy composites and to study their tensile, flexural and chemical properties. The present work consists of the following specific objectives.
\end{abstract}

- Preparation of composite specimens by using the raw materials of glass fibre.

- By varying weight content ratio.

- Test the composite specimen by Universal Testing machine.

- Find out the tensile, flexural and chemical properties of composite specimens of glass fibre.

Keywords: PMC: PVA: NOTATION:

\section{INTRODUCTION}

After making and controlling fire and inventing the wheel, spinning of continuous yarns is probably the most important development of mankind, enabling him to survive outside the tropical climate zones and spread across the surface of the Earth. Flexible fabrics made of locally grown and spun fibres as cotton; flax and jute were a big step forward compared to animal skins. More and more natural resources were used, soon resulting in the first composites; straw reinforced walls, and bows and chariots made of glued layers of wood, bone and horn. More durable materials as wood and metal soon replaced these antique composites.

General tendency of the man is to lead comfortable life. For that he needs newer useful materials .quest for the newer materials has been going on since times immemorial. Many new materials have been developed in the $20^{\text {th }}$ century. Composite is one such material, which has revolutionized the concept of high strength and light weight materials.

\footnotetext{
${ }^{1}$ Dept. of M .E,GPCET,Kurnool-518452,India

2 Dept. of M .E,GPCET,Kurnool-518452,India
} 
A composite material is made by combining two or more materials-often ones that have very different properties. The two materials work together to give the composite unique properties. However, within the composite you can easily tell the different materials apart as they do not dissolve or blend into each other.

Composites are not new to mankind. Natural composites exist both in plants and animals. Wood is a composite-it is made from long cellulose fibres (a polymer) held together by a much weaker substance called lignin. Cellulose is also found in cotton, but without the lignin to bind it together it is much weaker. The two weak substances - lignin and cellulose together form a much stronger one.

The bone in our body is also a composite. It is made from hard but brittle material called hydroxyapetite (which is mainly calcium phosphate) and a soft and a flexible material called collagen(which is a protein).collagen is also found in hair and finger nails. On its own it would not be much use in the skeleton but it can combine with hydroxyapetite to give bone the properties that are needed to support the body.

Most composites are made of just two materials. One is the matrix or binder. It surrounds and binds together the fibres or fragments of other material, which is called the reinforcement.

The first modern composite was fibre glass. It is still widely used today for boat hulls, sports equipment, building panels and many car bodies. The matrix is plastic and the reinforcement is glass that has been made into fine threads and often oven into sort of cloth. On its own the glass is very strong but brittle and it will break when bent sharply. The plastic matrix holds the glass fibre together and also protects them from damage by sharing out the forces acting on them.

The urge to improve the properties of composite materials has prompted material scientists to investigate composites with lower reinforcement size, leading to the developments of composites. Depending on the type of polymer matrices, they are classified as thermosetting composites and thermoplastic composites. For the last three decades, the use of PMC has increased tremendously and this drastic growth is expected to continue in the future. The composites possess many useful properties such as high specific stiffness and strength and strength, dimensional stability, adequate electrical properties and excellent corrosion resistance. The implications are easy transportability, low stress for rotating parts, high ranges for rockets and missiles, which make them attractive for both the civil and defence applications. The composite industry is currently dominated by thermosetting resins

Namely epoxy, vinyl ester, unsaturated polyester, phenol, polyamides, cynate ester etc. This is because of their availability, relative ease of processing, lower cost of capital equipment for processing and low material cost.

The reinforcing phase of composite materials provides the strength and stiffness. In most cases, reinforcement is harder, stronger and stiffer than the matrix. The reinforcement is usually a fibre or particulate. Particulate composites have dimensions that are approximately equal in all directions. They may be spherical, palets or any other regular or irregular geometry. Particulate composites tend to be much weaker and less stiff than the continuous fibre composites. but they are usually much less expensive. Particulate reinforced composites usually contain less reinforcement (up to 40 to 50 volume percent) due to processing difficulties and brittleness.

A fibre has a length that is much greater than its diameter. The length to diameter ratio is known as aspect ratio and can vary greatly. Continuous fibres has long aspect ratios, while discontinuous fibres has short aspect ratios. Continuous fibres normally have a preffered orientation, while discontinuous fibres have random orientation.

Glass fibres are manufactured by drawing molten glass into very fine threads and then immediately protecting them from contact with the atmosphere or with hard surfaces in order to preserve the defect free structure that is created by the drawing process. Glass fibres are as 
strong as any of the newer inorganic fibres but they lack rigidity on account of their molecular structure. The properties of the glasses can be modified to a limit extent by changing the chemical composition of glass, but the only glass used to any great extent in composite material is ordinary borosilicate glass, known as E-glass .the largest volume usage of composite material involves E-glass as the reinforcement. S-glass (called R-glass in France) has somewhat better properties than E-glass, including higher thermal stability, but its higher cost has limited the extent of its use.

The increasing use of composite materials as revolutionized the aerospace industry over the past two decades.tha ability to vary the properties and performance of composite materials have been in large measure responsible for the great impact that these materials have had, traditionally, advanced composites structures have been fabricated from tape prepress, which were systematically stacked to form a laminate. This type of construction tends to give optimal in-plane stiffness and strength. Since the primary loads usually are in-plane, the use of such composites appeared logical. However, there are many situations where neither primary nor secondary loads are in-plane.in such situations, tape prepress may not be most appropriate, the future for composites is undergoing a transition. The aerospace performance criteria consisting of high specific stiffness and high specific strength are being supplement with high toughness and efficient manufacturability.

Many composites used today are at the leading edge of materials technology, enabling their use in advanced applications such as aircraft and aerospace structures. The idea of using composite materials, however, is not a new or recent one but has been around for thousands of years. The ancient Egyptians used chopped straw to reinforce mud bricks, and warriors used a composite consisting of bullock tendon, horn, bamboo strips, silk and pine resin it produce high - performance archery bows.

Since the early 1960s there has been an increase in the demand for stronger, stiffer and lighter materials for use in the aerospace, transportation and construction industries. In addition to high fatigue strength to weight ratio and fatigue damage tolerance of many composites also makes them an attractive option. As a result, composite materials are rapidly being utilized in industries that have traditionally used metals and are now at the forefront of research and development in many related areas.

\section{AIM AND SCOPE OF THE PRESENT WORK}

Due to their outstanding properties, polymers owe their servicing to the society to the maximum extent. Unfortunately at the same time they are possessing many environmental problems due to their non-degradable nature. It is the primary duty of all citizens in general and polymer scientists in particular to see that the polymers do not pollute the environment.

We used epoxy resin and PVA was used as the matrix components and glass fibre as reinforcement. To meet the specific needs composites have to be modified. Composites were prepared using hand-layup process technique.

\section{HAND LAY-UP}

Hand lay-up is the simplest and oldest open moulding method of the composite fabrication processes. It is a low volume, labour intensive method suited especially for large components, such as boat hulls. Glass or other reinforcing mat or woven fabric or roving is positioned manually in the open mould, and resin is poured, brushed, or sprayed over and into the glass plies. Entrapped air is removed manually with squeegees or rollers to complete the laminates structure. Room temperature curing polyesters and epoxies are the most commonly used 
matrix resins. Curing is initiated by a catalyst in the resin system, which hardens the fibre reinforced resin composite without external heat. For a high quality part surface, a pigmented gel coat is first applied to the mould surface.



Fig1:Hand lay-up

As the performance of the composite not only depends on the selection of the constituent materials, but also on the bonding between them. We also designed and developed the glass moulds for preparing the specimens for different tests.

\section{RESULTS}

The effect of some acids, alkalis and solvents on the composites under study is presented in table. From the table it is clearly evident that for composite, the weight gain is observed after immersion. This is understandable as the matrix is cross linked and as a result formation of gel takes place instead of dissolution. It is also observed that the effect of nitric acid and acetic acid is negligible on the composite and matrix. Further the water absorption by the composites was also found to be negligible. Basing on the chemical resistance and water absorption, composites can be put to use as water storage tanks.

Table-1 Resistance of glass fibre reinforced composite to chemical reagents

\begin{tabular}{|l|c|c|}
\hline Chemicals & Weight before test(mg) & Weight after test(mg) \\
\hline $40 \%$ nitric acid & 0.20 & 0.22 \\
\hline $10 \%$ hydrochloric acid & 0.19 & 0.22 \\
\hline $8 \%$ Acetic acid & 0.18 & 0.18 \\
\hline $10 \%$ Sodiumhydroxide & 0.18 & 0.19 \\
\hline $20 \%$ Sodium corbonate & 0.16 & 0.17 \\
\hline $10 \%$ Ammonium hydroxide & 0.15 & 0.20 \\
\hline Benzene & 0.17 & 0.27 \\
\hline
\end{tabular}

\begin{tabular}{|l|l|l|}
\hline Toulene & 0.19 & 0.22 \\
\hline Carbon tetrachloride & 0.16 & 0.19 \\
\hline Water & 0.12 & 0.12 \\
\hline
\end{tabular}

\section{CONCLUSION}

The experimental investigations on tensile and flexural behaviour of glass fibre reinforced epoxy composites with different weight percent of glass fibres have been carried out. The conclusions drawn from the present work are

1. The tensile strength of the composites varied from $34.13 \mathrm{MPa}$ to $79.47 \mathrm{MPa}$ and the maximum is obtained for composite with 30 grams glass fibre. 
2. The maximum tensile modulus of elasticity is obtained for the composite with 30 grams of glass fibre.

3 . The flexural strength of the composite varies from $116.40 \mathrm{MPa}$ to $232.84 \mathrm{MPa}$. The maximum flexural strength is obtained for the composite with 30 grams of glass fibre.

4. In the chemical test performed some chemicals like Acetic acid and Water shows negligible effect and the material can be used for water storage tanks.

From our experiment we conclude that as the composite materials are light in weight and have good mechanical properties we can replace conventional materials with composite materials.

\section{RESULT AND DISCUSSION}

From the fabricate composites, test specimens are prepared as per ASTM standards and are tested to evaluate their tensile and flexural strength. The results obtained by conducting these are given below.

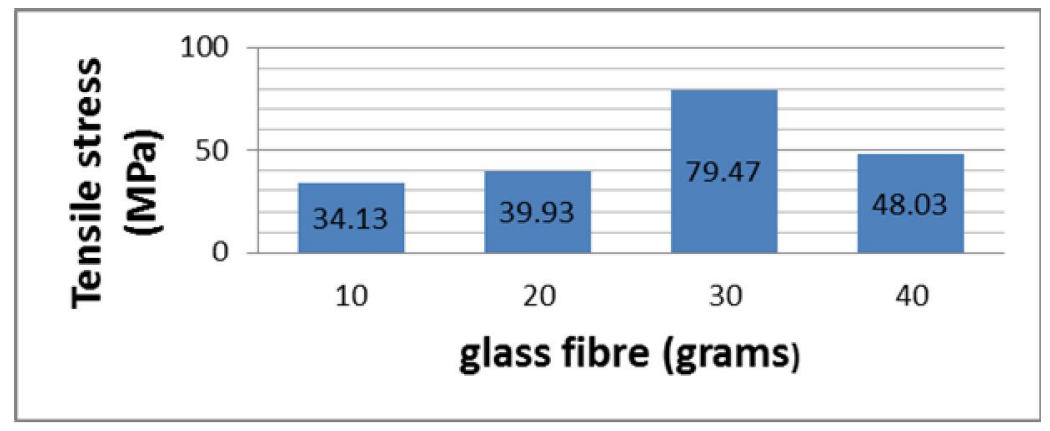

Fig 6.1: Variation of different grams of glass fiber and its tensile strength

\section{Tensile strength:}

The effect of the glass fibre on the tensile strength is shown in fig. It is observed that tensile strength varies from $34.13 \mathrm{MPa}$ to $79.47 \mathrm{MPa}$.the tensile strength increases with increase in glass fibre up to 30 grams and thereafter it decreases. The increase in tensile strength with increase in glass fibre can be attributed to good interfacial bonding between the glass fibre and the matrix. As the glass fibre content is further increased the composite transforms into brittle and hence the tensile strength decreases.

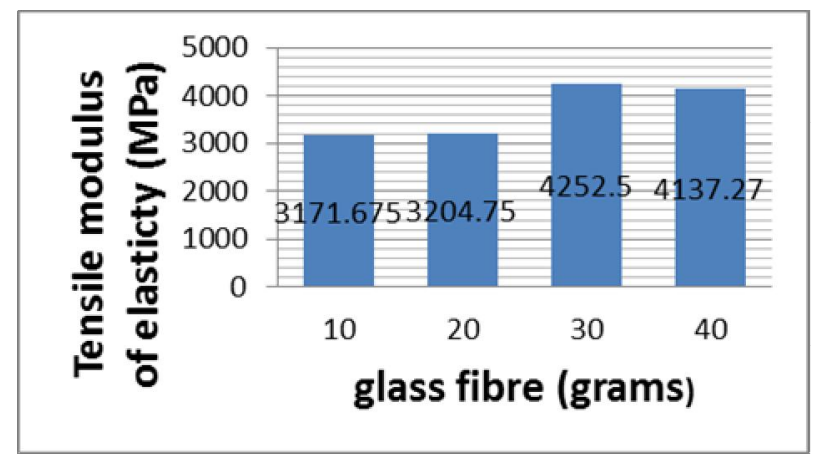

Tensile modulus of elasticity

Fig6.2: Variation of different grams of glass fiber and its tensile modulus of elasticity 
The above figure shows the effect of glass fibre on the tensile modulus for various compositions. The tensile modulus of elasticity varies from $3171.675 \mathrm{MPa}$ to $4252.5 \mathrm{MPa}$ and the maximum is obtained for the specimen with 30 grams of glass fibre.

\section{Flexural strength:}

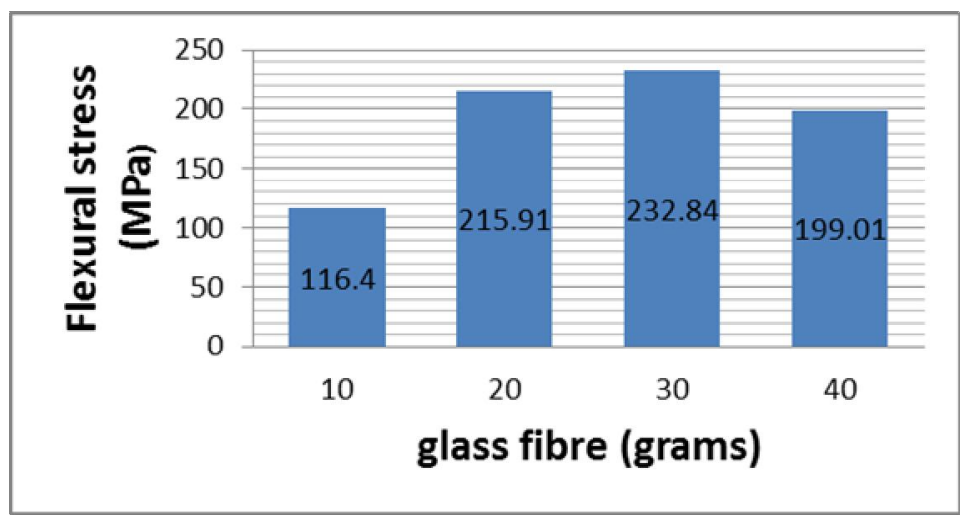

Fig 6.3:Variation of different grams of glass fiber and its flexural strength

The flexural strength is determined on Universal Testing machine from 3point bend test. The flexural stress for various compositions is shown in above figure.the flexural strength of the composite varies from $116.4 \mathrm{MPa}$ to $232.84 \mathrm{MPa}$ and the maximum is obtained for the composite with glass fibre of 30 grams.

\section{Flexural modulus of elasticity:}

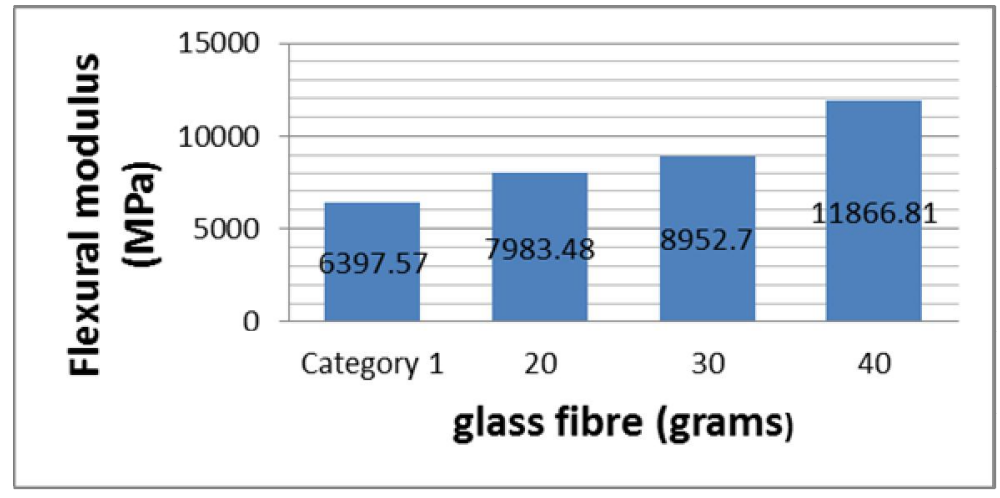

Fig 6.4:Variation of different grams of glass fiber and its flexural modulus of elasticity

The above figure shows the effect of the glass fibre on the flexural modulus for various compositions. Flexural modulus varies from $6397.57 \mathrm{MPa}$ to $11866,81 \mathrm{MPa}$.From above figure it is observed that flexural modulus goes on increasing with increase of glass fibre.

\section{REFERENCES}

[1]. Mayer, Rayner M. (1993). Design with reinforced plastics. Springer

[2]. US, "Method \& Apparatus for Making Glass Wool", published 11 Nov 1933, issued 11 Oct 1938

[3]. Marsh, George (8 Oct 2006). "50 years of reinforced plastic boats". Reinforced plastics. Elsevier Ltd.

[4]. Notable Progress - the use of plastics, Evening Post, Wellington, New Zealand, Volume CXXVIII, Issue 31, 5 August 1939, Page 28

[5]. Hobart, Tasmania "Car of the future in plastics". 
[6]. Gordon, J E (1991). The New Science of Strong Materials: Or Why You Don't Fall Through the Floor. Penguin Books Limited.

[7]. Fitzer, Erich; Kleinholz, Rudolf; Tiesler, Hartmut et al. (15 April 2008). "Fibers, 5. Synthetic Inorganic". Ullmann'sEncyclopedia of Industrial Chemistry. Ullmann's Encyclopedia of Industrial Chemistry 2. Weinheim, Germany: Wiley-VCH Verlag GmbH \& Co. KGaA.doi:10.1002/14356007.a11_001.pub 2. ISBN 3527306730.

[8]. "Fiberglass". redOrbit.com. Retrieved 28 Aug 2014.

[9]. "Guide to Glass Reinforced Plastics". East Coast Fibreglass Supplies.

[10]. Forbes Aird (1996). Fiberglass \& Composite Materials: An Enthusiast's Guide to High Performance NonMetallic Materials for Automotive Racing and Marine Use. 